\title{
Design and Analysis of a Kind of Centralized Forced Flip-Flow Screen
}

\author{
Chusheng Liu, Zhenqian Wang*, Jida Wu, Mengqi Zou, Wei Zhao and Wenqiang Qiu \\ School of Mechatronic Engineering, China University of Mining and Technology, Xuzhou, China
}

\begin{abstract}
During the dry screening, the hole plugging is a serious problem for most traditional screening equipment sieving the moist fine coal. It would lead to the low preparation efficiency and the low screening efficiency. The flip-flow screen is a new kind of screening equipment by using flip-flow motion of elastic screen surfaces to implement the separation of material. With the remarkable advantages of the extraordinary vibration intensity of screen surface, the hole is difficult to be plugged, and the screening efficiency is improved. In this paper, a kind of centralized forced flip-flow screen (CFFS) was proposed based on the crank rocker mechanism. The flip-flow motion of elastic screen surfaces is achieved by the periodical reversed motion of inner and outer screen boxes driven by crank. The advantages of the CFFS include considerable deformation of the screen surface, stable flip-flow quantity, low working noise, low vibration influence on environment, etc. The principle and construction of the CFFS were introduced, and the modal analysis and harmonic response analysis of key components (the crank and the linkage) were implemented based on finite element method (FEM), respectively. The first six orders of natural frequency and vibration modes were obtained. The maximum equivalent stress and strain under working and resonance frequency were achieved. The results illustrate that the resonance frequency is much higher than the working frequency, and the stress and strain are all within the safe limit of the material. The prototype was manufactured, and the sieving experiment demonstrates that the CFFS perform steadily, and screening efficiency is over $80 \%$. The new feasible method of the dry screening was proposed by the CFFS. The corresponding numerical simulation and the experiment provided a reliable basis for the future promotion of similar product design and research.
\end{abstract}

Keywords: flip-flow screen, centralized forced, modal analysis, sieving experiment, water content, fine particles

\section{Background}

Coal is the main energy source in China, and has accounted for about $70 \%$ in primary energy consumption (General Office of the State Council of the People's Republic of China 2014, Ministry of Land and Resources of the People's Republic of China 2014, Chen 2012). The mechanized coal mining technique is commonly used in current. Which results in a high degree of fragmentation of coal seam (Liu 2013, Fan 2013). And the influence of bunker underground and dropping belt also lead to the high degree of coal fragmentation and the low lump coal rate of coal out of wells. The use of technical measures of hydraulic mining and underground sprinkler dust, lead to an increase in raw coal fine grade coal rock composition and moisture content of the waste rock mud, coal bonded into a group. During dry sieving of the moist fine coal, the problems of sieve paste hole and plugging holes occur seriously with the reduction of screening efficiency. Which also results in that large amount of coal cannot be sorted, the commercial coal moisture increase, and the heat reduce. Consequently, the quality of coal is difficult to guarantee. The burden on the system of slime water is increasing, and numerous slime can be generated. To solve all these problems, as the new type of screen, flip-flow screen is applied to some coal preparation plants in recent years.

The flip-flow screen was originated in the 1960s. It was a screen of throwing material by flipping and flowing of screen surfaces. The flip-flow screens applied in industry currently mainly includes, the second generation Torwell flip-flow screen, the third generation Liwell screen of Germany, ГЭДП screen of Soviet Union, and BiviTEC-CRL screen of Austria (Dong 2012a). The main feature in common is that the mesh of flip-flow screen is made of scalable urethane rubber. The screen meshes flip and flow alternately in screening process. So that the material on the screen surface could entrain forward motion. The acceleration that screen surface generated can be greater than the cohesive force. That material adhered to the screen could be avoided. The large deflection of screen surface resulted in the formation of "breathing effect". That material clogged the screen could be prevented. The flip-flow screen holds advantages with large capacity of the unit area, high efficiency and plug prevention. But the disadvantages also remain, such as high energy consumption, high noise, large dynamic load, and screen surface vulnerability.

\section{The Main Structure of the CFFS}

In the purpose solving the problems mentioned above, China University of Mining and Technology developed CFFS with simple structure, smooth movement, low energy cost, and long working life (Zhao 2000, Liu 2010). The main structure of which is shown in Figure 1.

* Corresponding Author: Z.Q. Wang, wangzhenqian1988@126.com, phone: +86 18361209834

Copyright @ 2017 Canamaple Academia Services, http://press.camdemia.ca

DOI: 10.15273 /gree.2017.02.041 


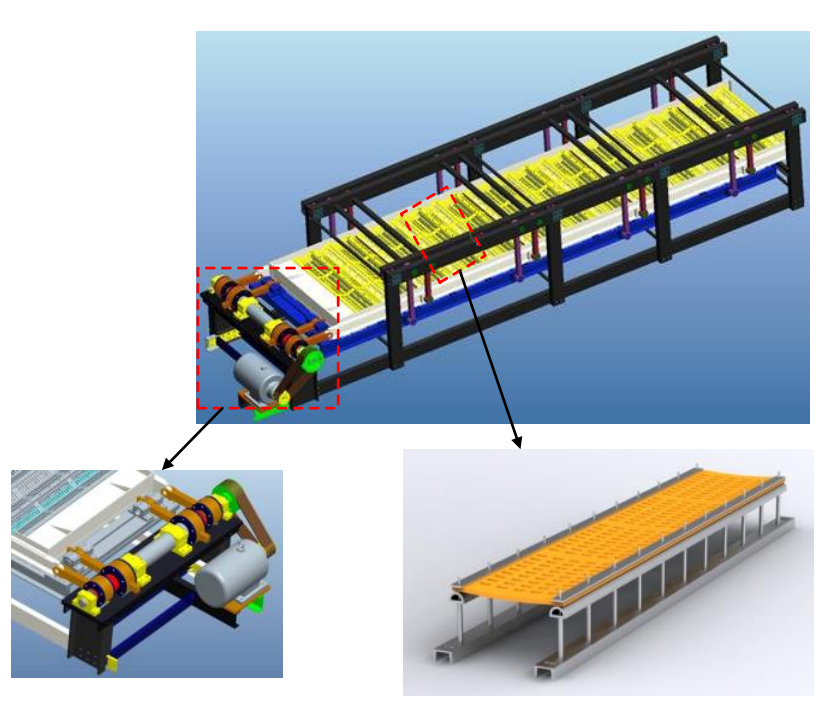

Figure 1. The main structure of CFFS.

The CFFS consists of motor, crankshaft, connecting rod, suspension mechanism, the screen frame, screen support structure, screen, and base. The screen frame is connected by suspension mechanism with the screen support structure. The energy generated by the motor is transmitted through the belt to the crankshaft. The crankshaft through screen frame drove by connecting rod was to do a reciprocating linear motion, and the screen mounted on the support beam of screen frame was driven to do flipping and flowing moving.

Since the shaft of driveline is designed as the combination of the crankshaft and belt, the symmetry of centering drive and inertial force can be achieved. Thus the overall force is uniform without twisting moment, and the errors on installation can be reduced. Through which the high reliability, nice integrative performance, smooth motion, convenience of assemblage can be obtained. Besides the life of the screen mesh can be improved as well.

Results from that the structure of CFFS is simplified comparing to the custom flip-flow screens, the weight of the CFFS is lighter. A screen with capacity of about $100 \mathrm{t} / \mathrm{h}$ weigh less than $2.5 \mathrm{t}$. As the weight is lighten and the structure is simplified, the energy consumption can be decreased. A screen with surface area of $6 \mathrm{~m}^{2}$ requires $5.5 \mathrm{~kW}$ motor power instead of $15 \mathrm{~kW}$ that the CZS flip-flow screen required with the same area. Thus cost of production and application can be reduced.

The design of the mesh support beam is optimized as well, as showed in Figure 1. The semi-cylindrical beam is used as the support frame of the screen, thus screen plate had no bending dynamic stress. Through which the reliability and life of screen plate can be improved (Yan 2011, Dong 2012b).

\section{Modal analysis of the Key Component of CFFS}

\subsection{Modal analysis of the crank}

During working, the inner and outer screen boxes are driven by the eccentric crank and the impact load with accompanying cyclic was imposed to it. The design of the cranks haft is significant for flip-flow screen. For estimating the vibration characteristics of crank to avoid the resonance at the motor operating frequency, the vibration mode and frequency of the crank was obtained by modal analysis.

The three-dimensional model of the crank was established by using Pro/E, which was imported into ANSYS Workbench with the format of STEP. The material of which was set as the default material of structural steel. According to the geometrical characteristics of the model, sweep tetrahedron grid and automatic grid was chosen, respectively, shown in Figure 2.

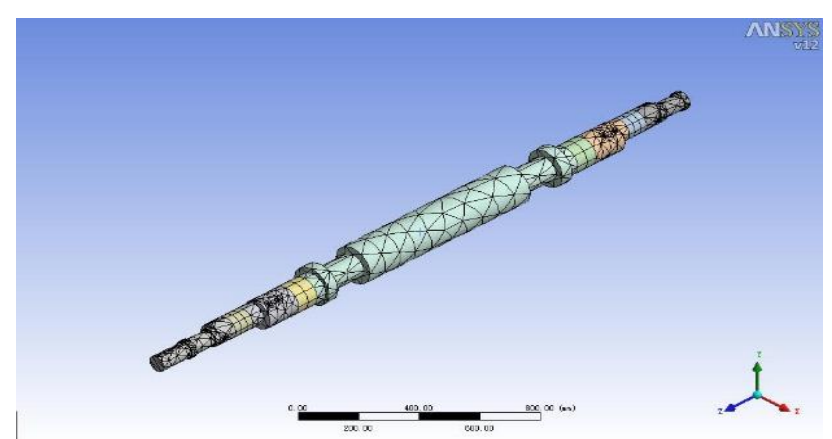

Figure 2. Section of the crank model and meshing.

The first six order modal vibration mode (Figure 3) and natural frequencies (Table 1) were obtained after calculation. The first order natural frequency is $219.56 \mathrm{~Hz}$, besides, natural frequencies after the second order are all above 800 $\mathrm{Hz}$, which stay far away from the general vibration frequency of the motor. So no resonance phenomenon can be aroused under normal conditions.

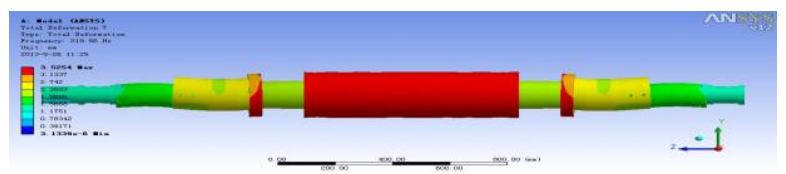

(a) the first order modal

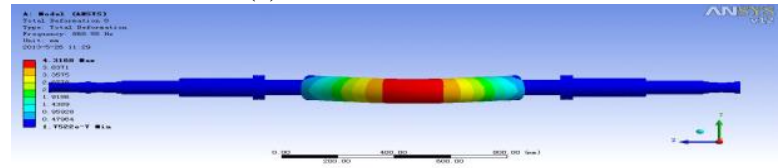

(b) the second order modal

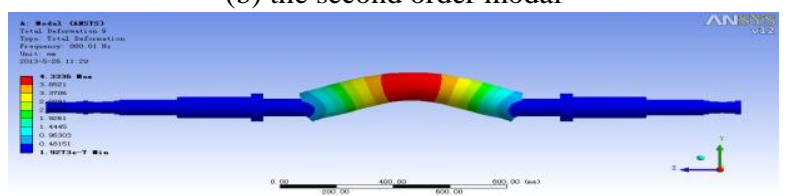

(c) the third order mode

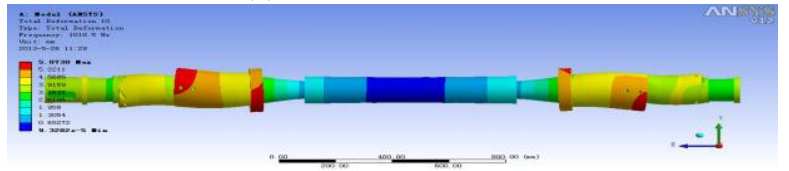

(d) the fourth order mode

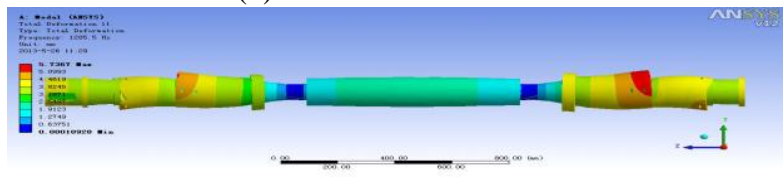

(e) the fifth order mode 


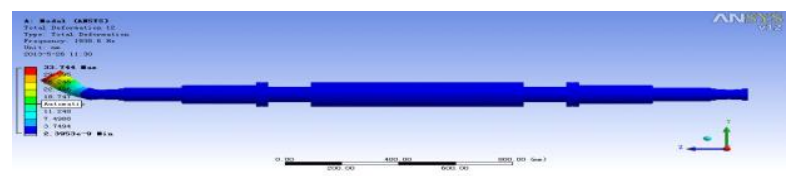

(f) the sixth order mode

Figure 3. The workbench modal analysis results of crank.

Table 1. Modal analysis results of the crank.

\begin{tabular}{|c|c|c|c|}
\hline Order & $\begin{array}{c}\text { Natural } \\
\text { frequency } \\
/ \mathrm{Hz} \\
\end{array}$ & Th.e modal results & $\begin{array}{l}\text { Maximum } \\
\text { amplitude } \\
/ \mathrm{mm} \\
\end{array}$ \\
\hline 1 & 219.56 & $\begin{array}{l}\text { Swelling-shrinking along the } \\
\text { radial as a whole }\end{array}$ & 3.5254 \\
\hline 2 & 868.55 & $\begin{array}{l}\text { Swings around along the } \mathrm{Z} \\
\text { axis }\end{array}$ & 4.3168 \\
\hline 3 & 880.01 & Bobbing along the $\mathrm{Z}$ axis & 4.3336 \\
\hline 4 & 1018.5 & $\begin{array}{l}\text { Two eccentric sections swell- } \\
\text { shrink along the } Z \text { axis }\end{array}$ & 5.8738 \\
\hline 5 & 1285.5 & $\begin{array}{l}\text { Two eccentric sections } \\
\text { swelling-shrinking along the } \\
\mathrm{Z} \text { axis and swinging }\end{array}$ & 5.7367 \\
\hline 6 & 1938.6 & $\begin{array}{l}\text { Pulley installation swing } \\
\text { around the } \mathrm{Z} \text { axis }\end{array}$ & 33.744 \\
\hline
\end{tabular}

\subsection{Harmonic response analysis of the crank}

In order to further analysis, the stress distribution of the crank under sinusoidal variation load, the harmonic response analysis was carried out on the basis of modal analysis. Connected with the previous modal analysis, harmonic response module in the ANSYS Workbench was used to load. Since the inertia force caused by the inner and outer screen boxes was equal and borne by the two eccentric sections, bearing load was applied on the four eccentric sections of crank, and the value was half of the amplitude along the Y direction. As shown in Figure 4, the torque was exerted on pulley by moment.

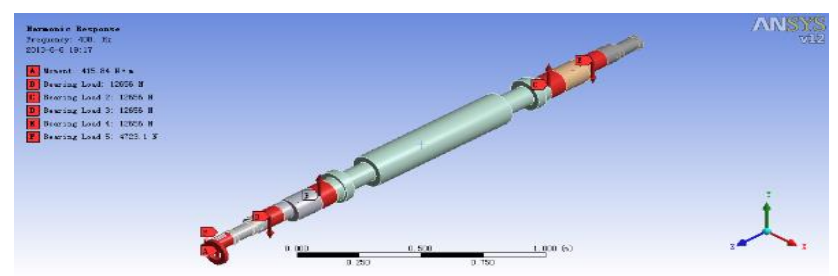

Figure 4. Applying inertia force and torque.

The frequency response curve was chosen from 400 to $1000 \mathrm{~Hz}$ on 20 intervals (Figure 5). According to the frequency response curve, the crank would resonance at 450 $\mathrm{Hz}$. When the crank resonated, danger would occur in the sliding bearing and eccentric junction which maximum stress value was $753.32 \mathrm{MPa}$ and maximum strain value was 0.0037. On the basis of the working frequency of the crank points $(9.1 \mathrm{~Hz})$ for harmonic response analysis, motor can be found on the excitation frequency of the crank that is much less than the resonance frequency of the crank, which the stress and strain of crank were within the safety of the material.
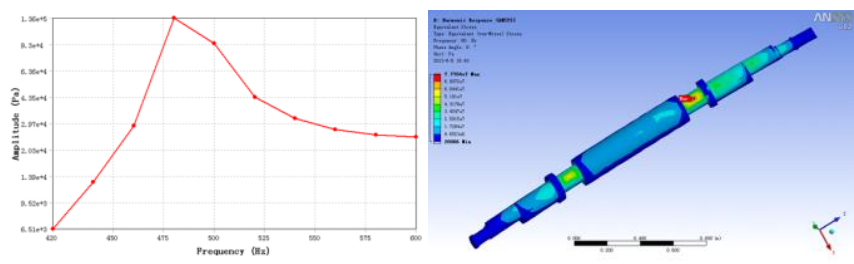

Figure 5. equivalent stress cloud atlas at working frequency.

\subsection{Modal analysis of the linker}

Modal analysis was carried out on the linker, the operation such as the import of the model, material and mesh setting are the same as the crank analysis above. Cylindrical that only keep rotational degree of freedom constraint was applied at the end circle, and the frictionless constraint limit the axial displacement was applied on the small circle. The results are shown in Table 2. The workbench modal analysis results of linker are shown in Figure 6.

Table 2. Modal analysis results of the linker.

\begin{tabular}{cclc}
\hline Order & $\begin{array}{c}\text { Natural } \\
\text { frequency } \\
/ \mathrm{Hz}\end{array}$ & \multicolumn{1}{c}{ The modal results } & $\begin{array}{c}\text { Maximum } \\
\text { amplitude } \\
/ \mathrm{mm}\end{array}$ \\
\hline 1 & 645 & Bobbing along the Y axis & 7.699 \\
\hline 2 & 706.11 & $\begin{array}{l}\text { Swings around along the } \\
\mathrm{X} \text { axis }\end{array}$ & 14.144 \\
\hline 3 & 2316.5 & $\begin{array}{l}\text { Sine twist along the X } \\
\text { axis }\end{array}$ & 11.229 \\
\hline 4 & 2993.7 & $\begin{array}{l}\text { Small round side swings } \\
\text { around along the X axis }\end{array}$ & 37.581 \\
\hline 5 & 3087.4 & $\begin{array}{l}\text { Small round side } \\
\text { separate from each other }\end{array}$ & 49.985 \\
\hline 6 & 3293.2 & $\begin{array}{l}\text { Twisting around the Z } \\
\text { axis }\end{array}$ & 21.318 \\
\hline
\end{tabular}

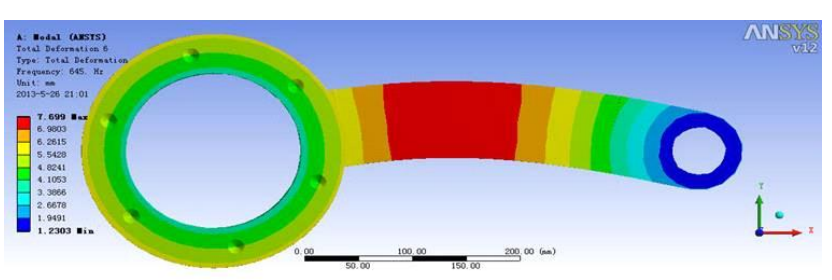

(a) first order mode shape

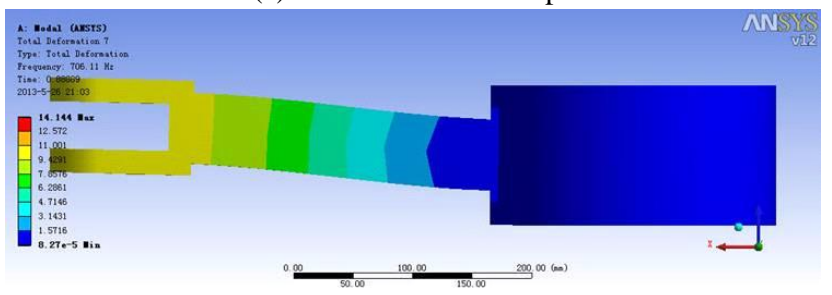

(b) the second order modal

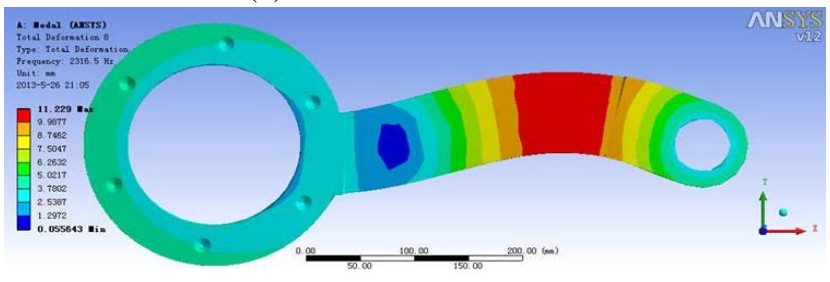

(c) the third order mode 


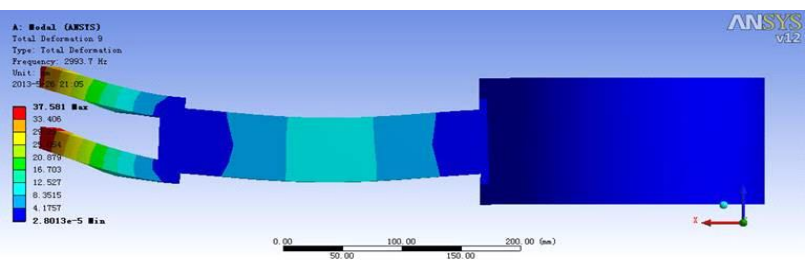

(d) the fourth order mode

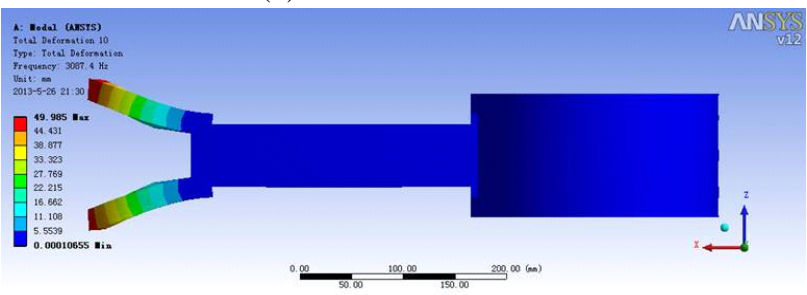

(e) the fifth order mode

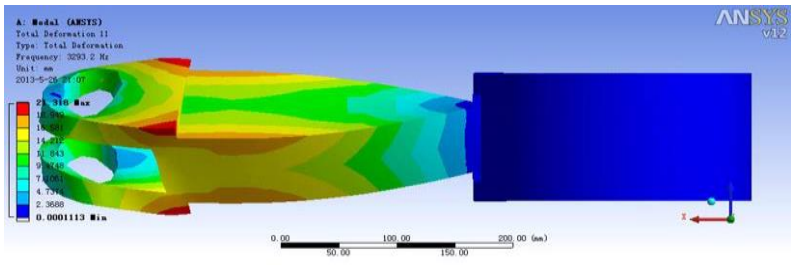

(f) the sixth order mode

Figure 6 . The workbench modal analysis results of crank.

\section{Sieving Experiment of CFFS}

The technological parameters of screening and kinematics parameters of flip-flow screen include the relations between the sieving indexes such as dynamic characteristic, screening efficiency (SE), undersize efficiency (UE), oversize efficiency (OE) and size composition of the sieved material, external moisture content, handling capacity (HC), and rational selection of screen slope, vibration angle, vibration frequency, amplitude. The research of these parameters can provides theoretical basis for selection of structural parameters and kinematics parameters of CFFS.

Screening efficiency (SE) refers to the ratio of amount of undersize product and the amount of material less than screen hole size contained in the feeding coal.

Undersize efficiency (UE) is the percentage of mass of undersized material and mass of all material.

Oversize efficiency (OE) is the percentage of mass of oversize material and mass of undersized material.

$$
\eta=\frac{100(\alpha-\theta)(\beta-\alpha)}{\alpha(\beta-\theta)(100-\alpha)} \times 100 \%
$$

where $\eta$-Screening efficiency (SE), \%

$\beta$-Percentage of material less than the screen hole size in the undersize material, $\%$

$\alpha, \theta$-Percentage of material less than the screen hole size in the feeding coal or oversize product, $\%$

In order to test the practical screening effect of CFFS accurately the prototype was manufactured, as shown in Figure 7. Sieving experiment was conducted based on GB/T477-2008 (Sieving experiment method for the coal).
The sieving experiment results of the raw coal are shown in Figure 8 and Figure 9.

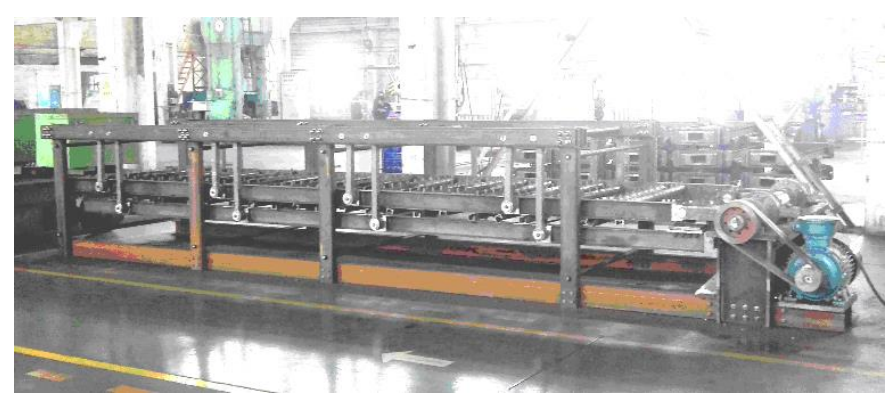

Figure 7. The prototype of the CFFS.

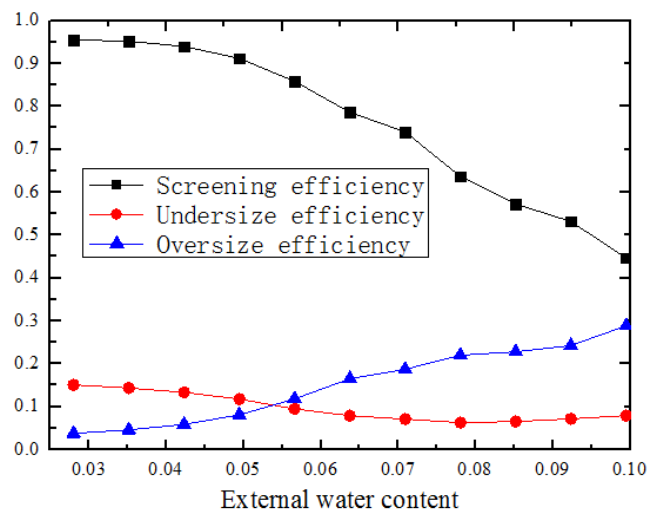

Figure 8. Relationship of the external water content to SE, UE, and OE.

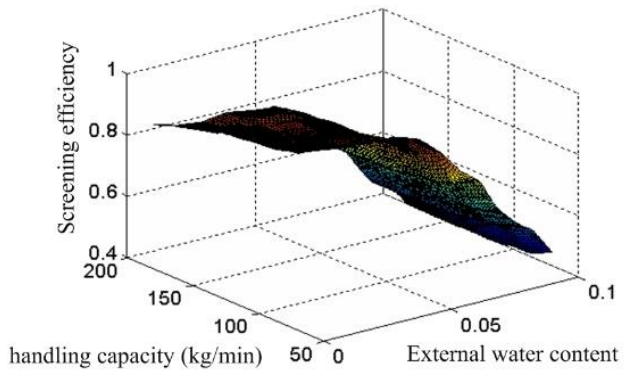

Figure 9. Effect of external water content and handing capacity on $\mathrm{SE}$ and $\mathrm{HC}$.

External water content may have a greater impact on the screening process of flip-flow screen. When the external water content is about $7 \%$, the screening efficiency of the flip-flow screen almost could remain the screening efficiency of $80 \%$ with undersize efficiency of less than $10 \%$ and oversize efficiency of about $15 \%$. It candidates that CFFS can perform depth screening for dry-cleaning method of moist fine coal excellently.

The screening efficiency of CFFS could maintain a stable level when external water content is constant and handling capacity is increased. When handling capacity is $200 \mathrm{~kg} / \mathrm{min}$ and external water content was $7 \%$, the screening efficiency of CFFS could reach more than $75 \%$. It shows that CFFS has a higher handling capacity for the moist fine coal. Therefore, CFFS has superior screening efficiency and can support bigger handling capacity at the 
same time when it is used to perform sieving of $-6 \mathrm{~mm}$ and $3 \mathrm{~mm}$ levels on moisture fine material.

Size composition of input is significant to the screening process. On the one hand, near-sized particle is probable to drive the screen blinding and it show influence on stratification of coarse and fine materials as well. On the other hand, the moist fine material is tend to cause screening blinding because of bonding when the content of it is increased. And it also reduce screening efficiency and increase mismatch ratio because the bonding fine particles may be expelled from output mixed with coarse material. During the screening process of CFFS, the screen holes conduct periodic open-close movement with great tossed acceleration result from that the screen surface has certain tensional amount and does elastic flexural movement. Thus, the screening blinding of various particles can be prevented, and the loosening and stratification of material can be promoted. Through which the screening efficiency can be improved.

Figure 10 shows the influence rule of fine material content under different external water contents to screening efficiency of CFFS. It can be seen that screening efficiency increases with the fine coal content when the external moisture content is constant. Because the elastic screen surface of CFFS has a very high tossed acceleration and it can prevent moisture fine material from blocking screen holes. The screening efficiency reaches the highest level of about $90 \%$ when the fine particle content is about $50 \%$. But the screening sufficiency is impacted by material layer because it is too thick to stratification when the fine material content is further increased.

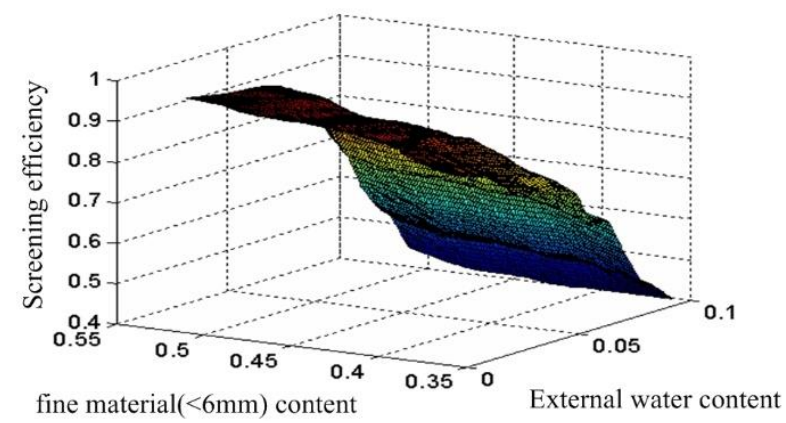

Figure 10. Effect of fine material content on screening efficiency under different external water contents.

\section{Conclusions}

(1) A finite element model of key parts of centralized forced flip-flow screen based on finite element technology was established, and the first 6 order natural frequencies and corresponding modes were obtained through numerical simulation. Through which the reliability was proved.

(2) The experimental study was conducted based on the prototype manufactured. It can be demonstrated that when the feed water and processing quantity changes, the CFFS can remain a strong applicability with a stable sieving performance.
(3) A new feasible method of dry screening was proposed by the CFFS, the corresponding numerical simulation and experiment provided a reliable basis for the future promotion of similar products design and research.

\section{References}

Chen, Q.R., 2012. Consideration of clean coal energy strategy in China. Journal of Heilongjiang Institute of Science \& Technology, 2012(4): 331 - 336.

Dong, H.L., 2012a. Study on the Dynamics of the Large Centralized Forced Flip-flow Screen Surface. Ph.D. Thesis, University of Mining and Technology, China.

Dong, H.L., Y.F. Xia and C.S. Liu, 2012b. Study on impact of structural reconstruction of support beam in flip-flow screen on reliability of screen surface. Mining \& Processing Equipment, 40(2): 71 - 74.

Fan, C.Q., H.Y. Zhao, L. Ji, M. Zeng, S.T. Qiu and J.J. Long, 2013. Development trend and the factors influencing working effect of flip-flow screen. Coal Preparation Technology, 2013(1): 88 - 90.

General Office of the State Council of the People's Republic of China, 2014. Strategic action plan for energy development (2014-2020). http://www.gov.cn/xinwen/201411/19/content_2780748 .htm.

Liu, C.S., Y.M. Zhao and Y.F. Xie, 2010. New advances in research and application of flip-flow screen. National Screening Technology Conference, 21(4): 547 - 552.

Liu, X.D., Z.R. Liang and K.F. Gao, 2013. Dry screening of wet raw coal. Coal Preparation Technology, 2013(3): $43-45$.

Ministry of Land and Resources of the People's Republic of China, 2014. Potential evaluation of national coal resources.

http://www.zmdxw.com/xinwenfabu/dongtai/newshow. asp?news_id $=1228$.

Yan, J.X., C.S. Liu, S.M. Zhang and H.P. Zhou, 2011. Dynamic analysis of sieving plate of centralized forced flip-flow screen. Mining \& Processing Equipment, 39(4): 95 - 97.

Zhao, Y., C. Liu, M. Fan and L. Wei, 2000. Research on acceleration of elastic flip - flow screen surface. International Journal of Mineral Processing, 59(4): 267 $-274$. 